\title{
A randomised controlled trial of structured nurse-led outpatient clinic follow-up for dyspeptic patients after direct access
}

\author{
gastroscopy \\ David Chan*1, Scott Harris ${ }^{2}$, Paul Roderick, David Brown ${ }^{3}$ and Praful Patel ${ }^{1}$
}

Address: ${ }^{1}$ Department of Gastroenterology, Southampton University Hospitals Trust, Southampton, UK, ${ }^{2}$ Public Health Sciences and Medical Statistics faculty, Southampton University, Southampton, UK and 3Pharmacology and Bio Medical Sciences faculty, Portsmouth University, Portsmouth, UK

Email: David Chan* - davidcchan@btinternet.com; Scott Harris - sharris@soton.ac.uk; Paul Roderick - pjr@soton.ac.uk; David Brown - david.brown@port.ac.uk; Praful Patel - praful.patel@suht.swest.nhs.uk

* Corresponding author

Published: 6 February 2009

BMC Gastroenterology 2009, 9:12 doi:10.1186/1471-230X-9-12

This article is available from: http://www.biomedcentral.com/I47I-230X/9//2

(c) 2009 Chan et al; licensee BioMed Central Ltd.

This is an Open Access article distributed under the terms of the Creative Commons Attribution License (http://creativecommons.org/licenses/by/2.0), which permits unrestricted use, distribution, and reproduction in any medium, provided the original work is properly cited.
Received: 10 April 2008

Accepted: 6 February 2009

\begin{abstract}
Background: Dyspepsia is a common disorder in the community, with many patients referred for diagnostic gastroscopy by their General Practitioner (GP). The National Institute of Clinical Excellence (NICE) recommends follow-up after investigation for cost effective management, including lifestyle advice and drug use. An alternative strategy may be the use of a gastro-intestinal nurse practitioner (GNP) instead of the GP. The objective of this study is to compare the effectiveness and costs of systematic GNP led follow-up to usual care by GPs in dyspeptic patients following gastroscopy.

Results: Direct access adult dyspeptic patients referred for gastroscopy; without serious pathology, were followed-up in a structured nurse-led outpatient clinic. Outcome measurement used to compare the two study cohorts (GNP versus GP) included Glasgow dyspepsia severity (Gladys) score, Health Status Short Form 12 (SFI2), ulcer healing drug (UHD) use and costs. One hundred and seventy five patients were eligible after gastroscopy, 89 were randomised to GNP follow-up and 86 to GP follow-up. Follow-up at 6 months was $81 / 89$ (91\%) in the GNP arm and 79/ $86(92 \%)$ in the GP arm. On an intention to treat analysis, adjusted mean differences $(95 \% \mathrm{Cl})$ at follow-up between Nurse and GP follow-up were: Gladys score 2.30 (I.4-3.2) P < $0.00 \mathrm{I}$, SFI2 $140.6(96.5-184.8) \mathrm{p}=<0.00 \mathrm{I}$ and UHD costs $£ 39.60(£ 24.20-£ 55.10) \mathrm{p}=<0.00 \mathrm{I}$, all in favour of nurse follow-up.
\end{abstract}

Conclusion: A standardised and structured follow-up by one gastrointestinal nurse practitioner was effective and may save drug costs in patients after gastroscopy. These findings need replication in other centres.

\section{Background}

Dyspepsia is a common complaint that leads to significant health care costs [1-3]. The management of dyspepsia and its related causes has progressed in recent years. In
England, the National Institute of Clinical Excellence (NICE), published recommendations (2004) to promote cost effective management [4]. Key recommendations were for follow-up, after direct access gastroscopy to 
maintain minimum effective therapy, to provide lifestyle advice and to perform an annual review. A large proportion of these patients are managed within primary care but the effectiveness of such care is unknown [5]. A contributory factor may be the limited time of a general practitioner's (GP) consultation and prioritisation of GP workload to more serious conditions. Other health-care professionals, such as gastrointestinal nurse practitioners (GNP), may be capable of taking on this role and provide more appropriate care within available resources.

This study describes a randomised controlled trial, which compared the effectiveness and impact on acid suppressant use and costs of a systematic GNP-led follow-up in an outpatient clinic to usual care by GPs, in patients with dyspepsia after direct access gastroscopy.

\section{Methods}

All GP surgeries in the catchment area of a teaching hospital referral centre (Southampton University Hospital Trust) were included. All direct access referrals for gastroscopy were screened to exclude those with sinister symptoms i.e. dysphagia, vomiting, anaemia, rapid weight loss or those with history of gastric surgery. Patients were consented at the point of recruitment. Trained medical endoscopists performed the gastroscopy procedure. Patients found to have peptic ulcer, tumour, severe oesophagitis (grade C and D), Barrett's oesophagus and anatomical abnormality were excluded. Patients included were those with mild gastro-oesophageal reflux disease (GORD non-erosive or grade A and B oesophagitis, hiatus hernia), non-ulcer dyspepsia (NUD) (mild and moderate gastritis or duodenitis) and those with normal findings.

Baseline details of socio-demographic factors, education, self-reported height and weight, smoking, alcohol (current versus non-drinker) and ulcer healing drugs (UHD) used in the past 6 months were collected by interview of all patients presenting for elective gastroscopy at Southampton University Hospitals Trust for the period between May 2002 to May 2004. All patients also completed two validated questionnaires relating to the past 6 months: the Glasgow Dyspepsia severity scores (Gladys) and the Health Status Short Form 12 (SF-12) [6,7]. After gastroscopy, endoscopists maintained their routine practice in giving verbal and written advice to patients and documented treatment recommendation to GPs in a formal report. Patients eligible for entry after endoscopy were randomised into intervention (GNP) and control (GP) groups, with a password protected, computer generated random number table. The endoscopists telephoned a separate office to obtain the follow-up status. The 'GNP' group was given one out-patient appointment. The 'GP' cohort was discharged and advised to see their GP.

In the nurse-led clinic, a full medical history was taken. The clinical management was structured, based on national and local guidelines, with reference to each patient's predominant symptoms. Patients were given counselling and lifestyle advice, supplemented with relevant locally devised leaflets i.e. reflux, non-ulcer dyspepsia, weight control, and an individualised treatment plan agreed with them. Further investigation such as the urea breath test, motility studies and barium meal were initiated if required, as per routine clinical practice. To ensure practice consistency and reproducibility, 'history taking' and 'lifestyle advice' proformas were devised and used.

\section{Follow-up}

A researcher blinded to the patients' study status and diagnosis, interviewed all participants by telephone, at a prearranged time suitable to the patient, six months after randomisation. Data collected were Gladys dyspepsia score, SF-12 score, self-reported UHD used and weight and a patient satisfaction questionnaire.

\section{Drug use and cost}

The use of UHDs for the six months before (baseline) and for 6 months after trial entry were summed and averaged according to class: Proton pump inhibitors (PPI) and Histamine $_{2}$ receptor antagonists $\left(\mathrm{H}_{2} \mathrm{RA}\right)$ and strength (half and full-dose PPI). Half-dose PPI and $\mathrm{H}_{2}$ RAs were grouped, as they were equivalent in costs. Drug use by month, based on quantity of tablets, was therefore grouped: 'full-dose PPI' vs 'half-dose PPI and $\mathrm{H}_{2} \mathrm{RA}$ ' vs 'no treatment'. Twice daily full-dose PPI was counted as 2 months and alternate days use counted as half a month. On demand therapy was recorded according to number of tablet/s taken per week and multiplied by 4 to give a monthly quantity. UHD prices were taken for each specific UHD from Monthly Index of Medical Speciality (MIMS 2006) and Drug Tariff (2006).

\section{Statistical analysis}

A sample size calculation indicated that a minimum of 186 patients, 93 in each group, would be needed to detect a 1 point of improvement on the Gladys dyspepsia scale with $80 \%$ power at the $5 \%$ significance level. This calculation was based on a standard deviation of 2.85 that came from a pilot study of 30 cases presenting for gastroscopy in which the Gladys scores were obtained before the procedure.

The two groups were compared by the change from baseline to month 6 in the key outcome variables - Gladys score, SF12 and overall UHDs cost, adjusted for baseline values by including the baseline levels of the outcome in the ANOVA as a covariate; $p<0.05$ was taken as being significant. Intention to treat analysis was undertaken by assuming the 15 patients with no 6 month follow-up data did not change from baseline. The component scales of SF12 and Gladys were analysed with p values calculated using the Mann-Whitney or Chi-square test where appro- 
priate; a $\mathrm{p}$ value of $<0.01$ was taken because of multiple testing.

Local ethics committee approval was obtained (reference no. 050-02) and the study registered with the Southampton University Hospitals NHS Trust Research Department.

\section{Results}

Over a 2 year period, on the elective direct access gastroscopy lists at which the GNP could attend, 199 unselected patients were approached and 196 (98.5\%) were recruited. One hundred and seventy five (89.3\%) patients were eligible after investigation. Of the 21 ineligible patients, 16 did not meet the criteria (Barrett's oesophagus: 6 , oesophagitis grade $\mathrm{C}$ : 2 , oesophageal stricture: 1 , peptic ulcer disease: 3, possible cancer: 1). Three cases were deemed unsuitable by the endoscopist, as symptoms were attributed to other conditions (rhinitis 1, angina 2).
Two did not have the procedure (failed intubation 1, food in stomach 1).

The 175 patients were randomised, 86 to GP follow-up (GP) and 89 to nurse follow-up (GNP). There were no obvious differences in the baseline characteristics of the two groups in age, BMI, smoking, alcohol and education status (see Table 1). The baseline Gladys scores (high scores equal higher burden of disease and symptoms) were similar (10.0 vs 9.9) but the SF12 scores (672.0 vs 627.7) were higher (high scores equal better health) in the GP group (see Table 1). The cost of UHD used, 6 months prior to the investigation, was lower in the GP group (£52.4 vs $£ 59.5)$.

\section{Intervention}

Early withdrawals (GP n $=3$ GNP $n=4$ ) after randomisation were experienced in both groups (Figure 1), Three in the 'GP' group decided not to see their GP. The four in the

Table I: Baseline characteristics of patients randomised to 'GP' and 'GNP' groups.

\begin{tabular}{|c|c|c|c|}
\hline & & \multicolumn{2}{|c|}{ Treatment group } \\
\hline & & $\begin{array}{r}\text { GP } \\
\mathbf{N}=86\end{array}$ & $\begin{array}{r}\text { GNP } \\
\mathbf{N}=89\end{array}$ \\
\hline Age yrs & Mean (SD) & $48.4(12.8))$ & $50.2(13.9)$ \\
\hline Gender & Male & $42(49)$ & $44(49)$ \\
\hline $\mathrm{BMI} \mathrm{kg} / \mathrm{m}^{2}$ & Mean (SD) & $27.5(5.0)$ & $27.0(5.8)$ \\
\hline \multirow[t]{4}{*}{ Smoking status } & Current & $23(27)$ & $24(27)$ \\
\hline & Ex & $43(50)$ & $42(47)$ \\
\hline & Non & $19(22)$ & $23(26)$ \\
\hline & Unknown & I (I) & $0(0)$ \\
\hline Alcohol & Drinker & $76(88)$ & $78(88)$ \\
\hline \multicolumn{4}{|l|}{ Education (grouping) } \\
\hline No qualifications & & $30(35)$ & 35 (39) \\
\hline 'O' levels \& vocational qualifications & & $22(26)$ & $20(22)$ \\
\hline 'A' levels to diplomas & & $11(13)$ & $12(13)$ \\
\hline Professional, | It $\&$ higher degrees $^{-}$ & & $23(27)$ & $22(25)$ \\
\hline Gladys score & Mean (SD) & $10.0(3.0)$ & $9.9(3.2)$ \\
\hline SFI2 & Mean (SD) & $672.0(157.3)$ & $627.7(197.930)$ \\
\hline UHD costs (based on following*) & Mean (SD) in $t$ & $52.4(47.6)$ & $59.5(46.3)$ \\
\hline *UHD types in previous 6 months & Months of use & & \\
\hline Full dose PPI & & $1.4(2.0)$ & I.5(2.0) \\
\hline Half dose $\mathrm{PPI}$ or $\mathrm{H} 2 \mathrm{RA}$ & & I.I(I.9) & I.5(2.2) \\
\hline None & & $3.4(2.2)$ & $3.0(2.2)$ \\
\hline
\end{tabular}

* Details of grouping in 'Statistical analysis'.

Figures are number $(\%)$ unless specified. 
'GNP' group were due to work commitments (2), leaving the area (1) and after own GP consultation (1). 78/89 $(88 \%)$ actually attended the GNP clinic compared to only $40 / 86(47 \%)$ in the GP arm.

In the GP arm, $12(30.0 \%)$ recalled not having had their gastroscopy findings explained, 23 (57.5\%) were given lifestyle advice and 5 (12.5\%) received dyspepsia information leaflets by their GPs. Most patients found the information given to them of limited use and most of them rated it ineffective in changing their lifestyle. In contrast, all those who attended the nurse-led clinic said that their gastroscopy findings were explained and receiving lifestyle advice with leaflets. Furthermore, most patients reported that this information enabled them to make positive lifestyle changes.

\section{6 month follow-up}

The response rate was high: $79 / 86(92 \%)$ in the GP arm and $81 / 89(91 \%)$ patients in the GNP arm (see Figure 1). Both groups had symptom improvement at 6 month follow-up but this was significantly better in the 'GNP' group (see Table 2) showing the Gladys score difference adjusted for baseline was $2.3(1.4-3.1, \mathrm{p}<0.001)$. The SF12 data also showed that the nurse group had the greatest improvement (140.7 (96.5-184.8) p < 0.001). 'GP' drug costs (per patient per week) rose by $£ 19.30$ and 'GNP'

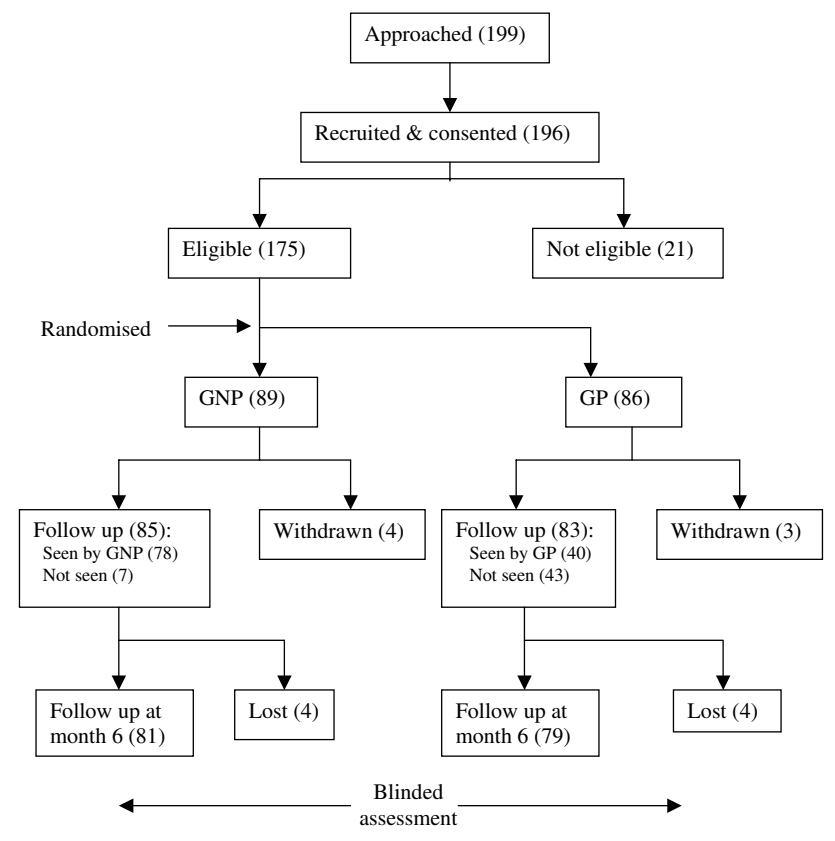

\section{Figure I}

This figure shows the number of patients approached, recruited, randomised to follow-up and seen by the Gastrointestinal nurse practitioner and GPs in both cohorts. group fell by $£ 24.30$ over the study period with a significant difference at 6 months $(£ 39.6(£ 24.2-£ 55.1) \mathrm{p}<$ $0.001)$.

Seven patients in each arm had a positive $H$. pylori test and received eradication therapy. The same number of patients (3) in each group had further tests. In the 'GP' group, 2 patients recalled having a urea breath test to confirm eradication success and 1 had abdominal ultra sound for epigastric pain; all had negative findings. Three patients in the 'nurse' group had 24-hour $\mathrm{pH}$ manometery studies, for volume reflux and severe GORD was confirmed. Two patients opted for surgical intervention. Criteria for further investigation by the nurse were according to routine clinical protocol for patients with severe and/or treatment resistant dyspeptic symptoms.

Of the nine domains in the Gladys questionnaire (see Table 3), four showed improvement in the 'GNP' group: reduced episodes of dyspepsia $(p=0.003)$, less dyspepsia interfering with normal activities $(\mathrm{p}<0.001)$, lower doctor visits (though this would be anticipated due to the design), and less prescribed UHDs ( $\mathrm{p}=0.001)$; no significant differences were seen in the remaining five. Seven out of twelve domains in SF12 (see Table 4) showed significant improvement in the 'GNP' group.

\section{Patterns of drug use}

The baseline UHD use was well matched (see Table 1) between the 2 groups. Over the 6 month follow-up period the GNP group consumed less months of 'full-dose PPI' medication $1.5(0.8-2.1) \mathrm{p}<0.0001$ and more had 'no treatment' $1.7(0.9-2.4) \mathrm{p}<0.001$. There were similar months of 'half-dose PPIs and $\mathrm{H}_{2}$ RAs'used in both groups (see Table 5).

\section{Discussion}

This is the first randomised controlled trial to investigate the effectiveness of nurse-led dyspepsia management compared to usual GP follow-up. A robust reproducible intervention to control symptoms and minimise medication was achieved by providing patients with appropriate information after OGD. The main findings were a significant reduction in symptom severity, an improvement in health related quality of life, and reduced anti-ulcer drug use and costs in the nurse-led group.

This trial followed established design principles with concealed allocation, minimal loss to follow-up, blinding of assessment and use of validated assessment instruments. It was a pragmatic study, which compared different professionals in different locations comparing current practice. The main limitation was the use of a single centre with only six-month follow-up. Longer follow-up would allow assessment of sustainability of the intervention, and 
Table 2: Comparison of key outcomes at 6 month follow-up between the 'GP' and 'GNP' groups.

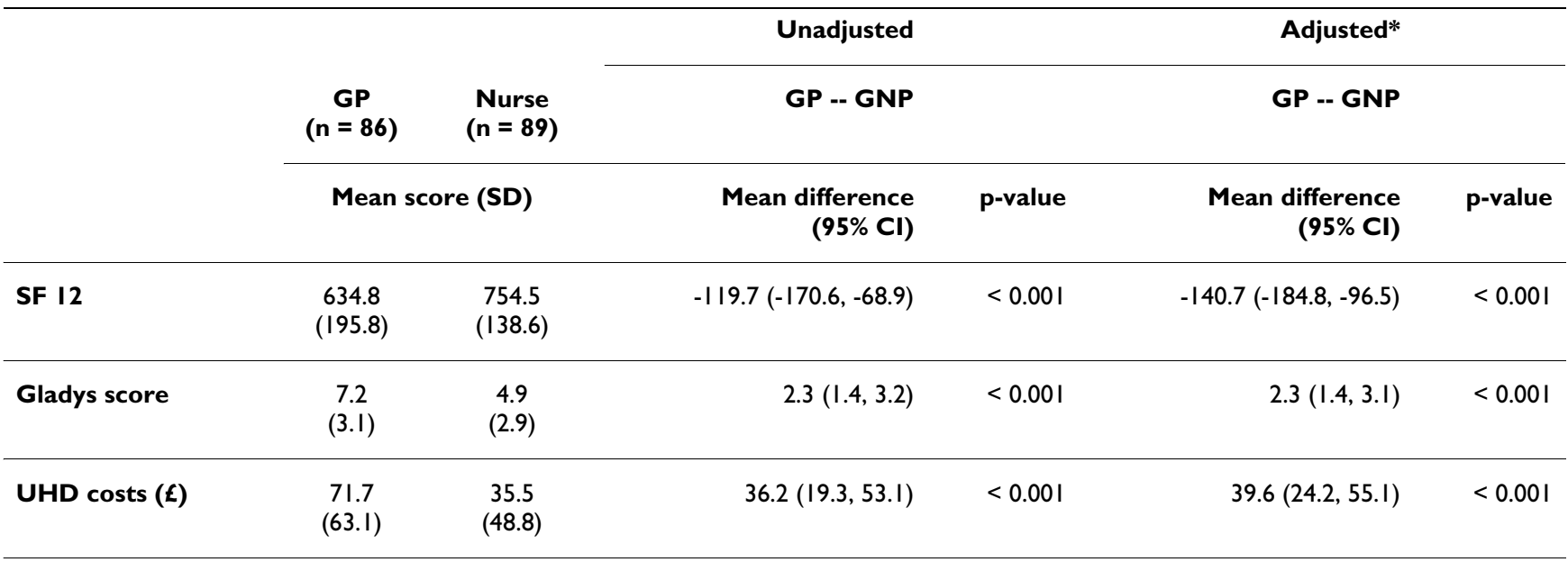

* Adjusted for baseline level using ANOVA.

increasing the number of centres would enhance generalisibility. A potential limitation was the lack of distinction between different diagnostic groups; with mixing of nonulcer type and reflux-type symptoms though appropriate lifestyle advice was provided based on predominant symptoms. We did not undertake full economic costing but rather focused on drug costs as the major component. The overall cost-effectiveness of this strategy need further evaluation taking into account all cost elements i.e. clinicians' time, additional investigation, surgical intervention and administrative support.

Previous studies have shown the beneficial effect of gastroscopy on patients' symptoms [8-10]. The outcome of this study shows that the additional interventions in the nurse-led clinic had added benefit; by reducing UHD costs on the background of improved symptoms and well being. The major differences between this and other upper GI nurse-led studies include the use of valid end-points, randomised design and estimation of the impact on drug cost [11-13]. This study demonstrates that investigation is not the end point of dyspepsia management; rather it provides clinicians with the means to formulate a personalised treatment plan and the importance of explanation, counselling and patient empowerment in managing their illness.

A contributory factor to the greater effectiveness of nurseled care might have been the low attendance rate (47\%) of patients to see their GPs after endoscopy, compared to the almost universal attendance at the nurse clinic. This emphasizes the need for appropriate advice even if patients are found to have minor or normal findings. Patient perspectives on the nurse clinic were very positive. The structured approach supported by locally devised lifestyle leaflets to reinforce this advice, may have motivated patients to self-care more effectively e.g. avoid late meals, reduce portion size, smoking, alcohol and caffeine and may have contributed to the outcome differences [14-18].

The cost of drugs used had increased by approximately one third at six months review in the 'GP' group. This increase was consistent with the Gladys questionnaire in 'over-the-counter' drug use. Dyspepsia is a symptomscomplex disorder and although UHDs may be effective in controlling acid-related symptoms, their use for non-acid related disorders are inadequate [19-22]. Thus with advice on healthy lifestyle and stress management, non-acid related symptoms could be controlled more effectively, leading to UHD reduction. In a wider context, nurse-led follow-up could augment medical care, improve general health and release doctors' time to focus on more complex cases. This may be an important strategy as more diagnostic endoscopy is carried out in primary care, though the effectiveness of nurse-led care within the primary care setting would need to be tested. The study did not examine GPs' satisfaction with nurse-managed care, as it has been established in other specialist nurse-led services [23-25].

It is conceivable that the strategy could be transferable to other specialist areas with less complex, high volume illnesses, e.g. irritable bowel syndrome, where time and counselling skills are required in addition to support from both medical and nursing professional bodies [26-29]. Furthermore, this is an agenda in the NHS reform of the care of patients with chronic illness in the community [30].

\section{Conclusion}

In conclusion, follow-up management of dyspepsia after direct access gastroscopy is variable. It can be standardised involving an experienced GNP, with sufficient time to give practical advice, which can empower patient to self-care effectively. This can lead to substantial health gains and 
Table 3: Comparison of individual Gladys questionnaire responses at 6 month follow-up.

\begin{tabular}{|c|c|c|c|c|}
\hline & & \multicolumn{2}{|c|}{ Treatment group } & \multirow[t]{2}{*}{ p value } \\
\hline & & GP & GNP & \\
\hline \multirow[t]{6}{*}{ Health limited social activities } & All of the time & $0(0)$ & $0(0)$ & $0.225{ }^{\dagger}$ \\
\hline & Most of the time & $I(I)$ & $2(3)$ & \\
\hline & A good bit of the time & I (I) & $0(0)$ & \\
\hline & Some of the time & $5(6)$ & $2(3)$ & \\
\hline & A little of the time & $6(8)$ & $4(5)$ & \\
\hline & None of the time & $66(84)$ & $73(90)$ & \\
\hline \multirow{6}{*}{ Over the last 6 months how frequent were indigestion symptoms } & Never & $7(9)$ & $10(12)$ & $0.003+$ \\
\hline & I or 2 days & $9(I I)$ & $21(26)$ & \\
\hline & I day per month & $15(19)$ & $16(20)$ & \\
\hline & I day per week & $22(28)$ & $22(27)$ & \\
\hline & $50 \%$ of days & $12(15)$ & $7(9)$ & \\
\hline & Most days & $14(18)$ & $5(6)$ & \\
\hline \multirow[t]{3}{*}{ Did indigestion interfere with normal activities } & Never & $21(27)$ & $44(54)$ & $<0.001 \dagger$ \\
\hline & Sometimes & $45(57)$ & $34(42)$ & \\
\hline & Regularly & $13(17)$ & $3(4)$ & \\
\hline \multirow[t]{3}{*}{ Days off work due to indigestion in 6 months } & None & $74(94)$ & $79(98)$ & $0.236{ }^{\dagger}$ \\
\hline & $\mathrm{I}-7$ days & $3(4)$ & I (I) & \\
\hline & More than 7 days & $2(3)$ & $I(1)$ & \\
\hline \multirow[t]{3}{*}{ Frequency of attending a doctor in 6 months } & None & $63(80)$ & $77(95)$ & $0.003+$ \\
\hline & Once & $6(8)$ & $2(3)$ & \\
\hline & Twice or more & $10(13)$ & $2(3)$ & \\
\hline \multirow[t]{3}{*}{ GP home visits due to indigestion in 6 months } & None & $79(100)$ & $81(100)$ & $1.000+$ \\
\hline & Once & $0(0)$ & $0(0)$ & \\
\hline & Twice or more & $0(0)$ & $0(0)$ & \\
\hline \multirow[t]{3}{*}{ Number of tests for indigestion in 6 months } & None & $76(96)$ & $78(96)$ & $0.975+$ \\
\hline & Once & $3(4)$ & $3(4)$ & \\
\hline & Twice or more & $0(0)$ & $0(0)$ & \\
\hline \multirow[t]{3}{*}{ Use of self-obtained medication in 6 months } & Never & $38(48)$ & $47(58)$ & $0.047 \dagger$ \\
\hline & Less than I/week & $19(24)$ & $26(32)$ & \\
\hline & More than I/week & $22(28)$ & $8(10)$ & \\
\hline \multirow[t]{4}{*}{ Use of prescribed drugs in 6 months } & Never & $15(19)$ & $31(38)$ & $0.001 t$ \\
\hline & I month or less & $8(10)$ & $14(17)$ & \\
\hline & I to 3 months & $8(10)$ & $8(10)$ & \\
\hline & More than 3 months & $48(61)$ & $28(35)$ & \\
\hline
\end{tabular}

† $P$ value from Mann-Whitney test.

Figures are number (\%).

reductions in drug costs in the community. This approach needs to be tested in other centres.

\section{Competing interests}

The authors declare that they have no competing interests.

\section{Authors' contributions}

DC conceived the study, participated in its design, acquisition of data, co-ordination and writing it up. SH partici- pated in the design and performed the statistical analysis. PR participated in the design, coordination and critical revision of the study. DB participated in the design and critical revision of the study. PP conceived the study, participated in the design, co-ordination and critical revision of the study. All authors read and approved the final manuscript. 
Table 4: Comparison of individual SFI 2 questions at 6 months follow-up.

\begin{tabular}{|c|c|c|c|c|}
\hline & & \multicolumn{2}{|c|}{ Treatment group } & \multirow[t]{2}{*}{ p value } \\
\hline & & GP & GNP & \\
\hline \multirow[t]{5}{*}{ General health } & Excellent & I (I) & $7(9)$ & $<0.001 t$ \\
\hline & Very good & $8(10)$ & $32(40)$ & \\
\hline & Good & $33(42)$ & $26(32)$ & \\
\hline & Fair & $35(44)$ & $15(19)$ & \\
\hline & Poor & $2(3)$ & $i(1)$ & \\
\hline \multirow[t]{3}{*}{ Health limited - Moderate activities } & Yes, limited a lot & $3(4)$ & $\mathrm{I}(\mathrm{I})$ & $0.261 t$ \\
\hline & Yes, limited a little & $15(19)$ & $12(15)$ & \\
\hline & No, not limited at all & $61(77)$ & $68(84)$ & \\
\hline \multirow[t]{3}{*}{ Health limited - Climbing several flights of stairs } & Yes, limited a lot & $6(8)$ & $2(3)$ & $0.021 \dagger$ \\
\hline & Yes, limited a little & $21(27)$ & $13(16)$ & \\
\hline & No, not limited at all & $52(66)$ & $66(82)$ & \\
\hline \multirow[t]{2}{*}{ Accomplished less than you would like in 4 weeks } & Yes & $27(34)$ & $8(10)$ & $<0.001 \ddagger$ \\
\hline & No & $52(66)$ & $73(90)$ & \\
\hline \multirow[t]{2}{*}{ Were limited in the kind of work or other activities in 4 weeks } & Yes & $22(28)$ & $7(9)$ & $0.002 \ddagger$ \\
\hline & No & $57(72)$ & $74(91)$ & \\
\hline Accomplished less than you would like & $\begin{array}{l}\text { Yes } \\
\text { No }\end{array}$ & $\begin{array}{l}22(28) \\
57(72)\end{array}$ & $\begin{array}{r}6(7) \\
75(93)\end{array}$ & $0.001 \ddagger$ \\
\hline \multirow[t]{2}{*}{ Didn't do work or other activities as carefully as usual } & Yes & $15(19)$ & $4(5)$ & $0.006 \ddagger$ \\
\hline & No & $64(81)$ & $77(95)$ & \\
\hline \multirow[t]{5}{*}{ Pain interfering with normal work in 4 weeks } & Not at all & 31 (39) & $42(52)$ & $0.023+$ \\
\hline & A little bit & $24(30)$ & $28(35)$ & \\
\hline & Moderately & $8(10)$ & $3(4)$ & \\
\hline & Quite a bit & II (14) & $8(10)$ & \\
\hline & Extremely & $5(60)$ & $0(0)$ & \\
\hline \multirow[t]{6}{*}{ Felt calm and peaceful } & All of the time & $5(6)$ & $5(6)$ & $0.024 \dagger$ \\
\hline & Most of the time & $17(22)$ & $31(38)$ & \\
\hline & A good bit of the time & $7(9)$ & $4(5)$ & \\
\hline & Some of the time & $35(44)$ & $36(44)$ & \\
\hline & A little of the time & $11(14)$ & $2(3)$ & \\
\hline & None of the time & $4(5)$ & $3(4)$ & \\
\hline \multirow[t]{6}{*}{ Had a lot of energy } & All of the time & $\mathrm{I}(\mathrm{I})$ & $3(4)$ & $0.002+$ \\
\hline & Most of the time & $13(17)$ & $24(30)$ & \\
\hline & A good bit of the time & $7(9)$ & $12(15)$ & \\
\hline & Some of the time & $33(42)$ & $29(36)$ & \\
\hline & A little of the time & $14(18)$ & $10(12)$ & \\
\hline & None of the time & $11(14)$ & $3(4)$ & \\
\hline \multirow[t]{6}{*}{ Felt downhearted and low } & All of the time & I (I) & $0(0)$ & $0.001 t$ \\
\hline & Most of the time & $6(8)$ & $I(I)$ & \\
\hline & A good bit of the time & $6(8)$ & $2(3)$ & \\
\hline & Some of the time & $30(38)$ & $24(30)$ & \\
\hline & A little of the time & $18(23)$ & $20(25)$ & \\
\hline & None of the time & $18(23)$ & 34 (42) & \\
\hline
\end{tabular}

† $P$ value from Mann-Whitney test.

$\neq \mathrm{P}$ value from Chi-square test.

Figures are number (\%). 
Table 5: Comparison of monthly UHD use at 6 month follow-up between 'GP' and 'GNP' groups.

\begin{tabular}{|c|c|c|c|c|c|c|}
\hline \multirow[b]{3}{*}{ Drug pattern in months } & \multirow[b]{2}{*}{$\begin{array}{c}\text { GP } \\
(n=86)\end{array}$} & \multirow[b]{2}{*}{$\begin{array}{c}\text { GNP } \\
(n=89)\end{array}$} & \multicolumn{2}{|l|}{ Unadjusted } & \multicolumn{2}{|l|}{ Adjusted* } \\
\hline & & & GP -- GNP & & GP -- GNP & \\
\hline & \multicolumn{2}{|c|}{ Mean score (SD) } & $\begin{array}{r}\text { Mean difference } \\
(95 \% \mathrm{CI})\end{array}$ & p-value & $\begin{array}{r}\text { Mean difference } \\
(95 \% \mathrm{Cl})\end{array}$ & p-value \\
\hline Full dose PPI & $2.0(2.7)$ & $0.6(1.7)$ & I.4 $(0.8,2.1)$ & $<0.001$ & I.5 $(0.8,2.1)$ & $<0.001$ \\
\hline Half dose PPIs & $1.5(2.4)$ & $1.4(2.3)$ & $0.0(-0.7,0.7)$ & 0.942 & $0.1(-0.5,0.8)$ & 0.702 \\
\hline No treatment & $2.5(2.7)$ & $4.0(2.5)$ & $-1.5(-2.2,-0.7)$ & $<0.001$ & $-1.7(-2.4,-0.9)$ & $<0.001$ \\
\hline
\end{tabular}

* Adjusted for baseline level.

† Including all $\mathrm{H}_{2} \mathrm{RAs}$.

\section{References}

I. Penston JG, Pounder RE: A survey of dyspepsia in Great Britain. Aliment Pharmacol Ther 1996, 10:83-9.

2. Moayyedi P, Forman D, Braunholtz D, Feltbower R, Crocombe W, Liptrott M, Axon A: The proportion of upper gastrointestinal symptoms in the community associated with Helicobacter pylori, lifestyle factors, and Nonsteroidal antiflammatory drugs. Am J Gastroenterol 2000, 95: | 448-55.

3. Logan R, Delaney B: ABC of the upper gastrointestinal tract: implications of dyspepsia for the NHS. $B r$ Med J 200I, 323(73 | 4):675-7.

4. Dyspepsia: Managing dyspepsia in adults in primary care. National Institute of Clinical Excellence guidance; 2004.

5. Chan D, Patel P, Lee D, Booth L, Shepherd HA: An audit of the use of long-term acid-suppressions in general practice: potential for large savings. [Abstract]. Gut 1997, 40(Suppl I):AI-A86. A60, F239

6. El-omar E, Banerjee S, Wirz A, McColl KEL: The Glasgow Dyspepsia Severity Score - a tool for the global measurement of dyspepsia. Euro J Gastroenterol Hepatol 1996, 8:967-71.

7. Ware JE, Kosinski M, Keller SD: SF-12 How to score the SF-I 2 physical and mental health summary scales. 2nd edition. Boston, MA: The Health Institute. New England Medical Centre; 1994.

8. Asante MA, Mendall M, Patel P, Ballam L, Northfield T: A randomised controlled trial of Endoscopy vs no Endoscopy in the management of seronegative $H$. pylori dyspepsia. Eur J Gastroenterol Hepatol 1998, I O( 1 2):983-989.

9. Bytzer P, Hansen JM, Schaffalitsky de Muckadell OB: Empirical $\mathbf{H}_{\mathbf{2}^{-}}$ blocker therapy or prompt endoscopy in management of dyspepsia. Lancet 1994, 343:8II-816.

10. Patel P, Khulusi S, Mendall MA, Lloyd R, Jazrawi R, Maxwell JP, Northfield TC: Prospective screening of dyspeptic patients by Helicobacter Pylori serology. Lancet 1995, 346(8986): |3| | -8.

II. Mason I: Audit of a newly established nurse-led dyspepsia triage clinic. Gastroint Nurs 2005, 3:25-3I.

12. Sadeghian J, Blanchard C, Shidrawi R: The nurse led dyspepsia clinic: A comparison with the medical model [abstract]. Gut 2004, A 1 07:416.

13. Kimble JE, Brooks CL, Gordon HM, Shepherd HA: An assessment of a nurse led Barrett's oesophagus follow up clinic [abstract]. Gut 2004, A 107:417.

14. Kitchin LI, Castell DO: Rationale and efficacy of conservative therapy for gastro-oesophageal reflux disease. Arch Intern Med |99|, I 5 |:448-54.

15. Holloway RH, Lyrenas E, Ireland A, Dent J: Effect of intraduodenal fat on lower oesophageal sphincter function and gastrooesophageal reflux. Gut 1997, 40:449-53.

16. Miller G, Palmer KR, Smith B, Ferrington C, Merrick ME: Smoking delays gastric emptying of solids. Gut 1999, 30:50-3.

17. Roberts DM: Chronic gastritis, alcohol and non-ulcer dyspepsia. Gut 1972, 13:768-74.
18. Wendl B, Pfeiffer A, Pehl C, Schmidt T, Kaess H: Effect of decaffeination of coffee or tea on gastro-oesophageal reflux. Aliment Pharmacol Ther 1994, 8:283-7.

19. Whitehead WE, Gibbs NA, Zhiming LI, Drossman DA: Is functional dyspepsia just a subset of the irritable bowel syndrome? Baillere's Clin Gastroenterol 1998, I 2:443-46I.

20. Talley NJ, Zinsmeister AR, Schleck CD, Melton LJ III: Dyspepsia and dyspepsia subgroups: a population-based study. Gastroenterology 1992, 102:1259-1268.

2I. Agreus L, Svardsudd K, Nyren O, Tibblin G: Irritable bowel syndrome and dyspepsia in the general population: overlap and lack of stability over time. Gastroenterology 1995, 109:67|-80.

22. Caballero-Plasencia AM, Sofos-Kontoyannis S, Valenzuela-Barraco M, Martin-Ruiz JL, Casado-Caballero FJ, Lopez-Manas JG: Irritable bowel syndrome in patients with dyspepsia: a communitybased study in Southern Europe. Eur J Gastroenterol Hepatol 1999, I1:517-522.

23. Laurent M, Reeves D, Hermens, Braspenning J, Grol R, Sibbald B: Substitution of doctors by nurses in primary care. Cochrane Library 2005:CD00I27I.

24. Connor C, Wright $C$, Fegan C: The safety and effectiveness of a nurse-led anticoagulant service. J Adv Nurs 2002, 38(4):407-4I5.

25. Moore S, Corner J, Haviland J, Wells M, Salmon E, Normand C, Brada M, O'brien M, Smith I: Nurse led follow up and conventional medical follow up in management of patients with lung cancer: randomised trial. $B M|2002,325:| \mid 45-55$.

26. Jones J, et al:: British Society of Gastroenterology guidelines for the management of the irritable bowel syndrome. Gut 2000, 47 Suppl 2:iil-iil 9.

27. Boyd-Carson W: Irritable Bowel Syndrome: Assessment and Management. Nursing Standard 2004, I 8(52):47-52.

28. Parker D: One woman's fight against an entire syndrome. Gastrointestinal Nursing 2004, 2(4): I0-12.

29. Royal College of Nursing. Care for people with colorectal problems. RCN competencies Project 2002.

30. Department of Health: NHS plan - a New Health Service [http://www.dh.gov.uk/en/Publicationsandstatistics/Publications/Publi cationsPolicyAndGuidance/Browsable/DH 4I27552]

\section{Pre-publication history}

The pre-publication history for this paper can be accessed here:

\section{http://www.biomedcentral.com/1471-230X/9/12/pre} pub 